\title{
COEFICIENTE DE ENDOCRUZAMENTO EM PORTADORES DE ESQUISTOSSOMOSE MANSÔNICA
}

\author{
José Tavares-Neto e Aluizio Prata
}

\begin{abstract}
$O$ coeficiente de endocruzamento (f ou de Wright) foi calculado em 1123 indivíduos de Catolândia, Bahia, área hiperendêmica da esquistossomose mansônica: 148 $(13,2 \%)$ tinham o coeficiente $f>0$. A forma hepatosplênica foi significantemente maior nos individuos com $f>0(26,8 \%)$. Nos brancos com $f>0$ o risco relativo foi de 14,1 ; enquanto, nos brancos com $f=0$, a freqüência da hepatosplenomegalia não diferiu dos não-brancos com $f=0 u f>0$. Com este coeficiente estimou-se a probabilidade de genes alélicos iguais, com origem em ancestral comum; os resultados reforçam a hipótese da regulação genética na susceptibilidade à forma hepatosplênica da esquistossomose mansônica.
\end{abstract}

Palavras-chaves: Coeficiente de endocruzamento. Schistosoma manson. Forma hepatosplênica.

A forma grave hepatosplênica, da esquistossomose mansônica, tem sido encontrada mais freqüentemente em individuos da raça branca. 42224 Recentemente, Tavares-Neto ${ }^{25}$ confirmou essa associação: predominância na raça branca enquanto os negróides e mestiço de índio (segundo classificação de Krieger e cols ${ }^{17}$ ) têm freqüência baixa dessa forma clínica. Também, Tavares-Neto \& Prata 26 constataram que nos indivíduos brancos há menos regressão da forma hepatosplênica, para a hepatointestinal, após terapêutica com oxamniquine. Ademais, a forma hepatosplênica da esquistossomose mansônica tem recorrência familial. 71527 Essas constatações reforçam a hipótese da contribuição do componente genético para o desenvolvimento da forma hepatosplènica.

Quando o risco de ocorrer uma patologia é proporcional ao coeficiente de endocruzamento (Beiguelman ${ }^{3}$ ), suspeita-se que na susceptibilidade a uma doença haja participação do componente genético. $\mathrm{O}$ nosso objetivo foi fazer essa avaliação na esquistossomose mansônica, em Catolândia, municipio situado no Planalto Ocidental Bahiano com alta prevalência de esquistossomose hepatosplênica. A região não tem casos de malária ou calazar.

\section{MATERIAL E MÉTODOS}

O coeficiente de endocruzamento de Wright $(f)$ foi estimado em residentes na área hiperendêmica da

Trabalho do Núcleo de Medicina Tropical e Nutrição da Universidade de Brasília com suporte financeiro do CNPq e do Ministério da Saúde.

Disciplina de Doenças Infecciosas e Parasitárias da Faculdade de Medicina do Triângulo Mineiro, Praça Thomaz Ulhoa 706, 38025 Uberaba-MG.

Recebido para publicação em 17/8/88. esquistossomose mansônica de Catolândia, Bahia, Brasil. Esse coeficiente indica a probabilidade de dois genes alelos no individuo serem iguais, por terem origem em qualquer ancestral comum. ${ }^{9} 18 \mathrm{Em} 265$ familias nucleares foi realizado heredograma e questionado ao casal sobre os ascendentes comuns. 27 As formas clinicas, hepatointestinal (HI) e hepatosplênica (HE), anteriores à terapêutica específica da esquistossomose mansônica, foram classificadas segundo Prata. ${ }^{21} \mathrm{~A}$ raça dos individuos foi classificada segundo Krieger e cols ${ }^{17}$ em: mestiço de índio (MI), branco (B), mulato claro (MC), mulato médio (MM), mulato escuro $(\mathrm{ME})$ e negro $(\mathrm{N})$

Para a análise estatística das associações, entre as variáveis, empregam-se métodos estatísticos nãoparamétricos, considerando-se $5 \%$ como o limite de significância.

\section{RESULTADOS}

Dos 1130 indivíduos residentes, o coeficiente de endocruzamento (f) foi avaliado em $1125(99,6 \%)$. Destes, $19(1,7 \%)$ individuos eram filhos de casais consangǘneos, porém não sabiam especificar os ascendentes comuns e dois foram excluidos, porque as informações eram imprecisas, restando, portanto, 1123 individuos, ou $99,4 \%$ da amostra inicial.

A distribuição do coeficiente de endocruzamento (f) nos 1123 individuos foi (n\%): $0(975 / 88,3)$, $1 / 4(2 / 0,2), 1 / 8(49 / 4,4), 1 / 16 \quad(35 / 3,2), 1 / 32$ $(23 / 1,2), 1 / 64(14 / 1,3), 1 / 128(6 / 0,5)$ e indeterminado، $f>0(19 / 1,7)$. Portanto, $13,2 \%(148 / 1123)$ dos individuos tinham $\mathrm{f}>0$; o que permite calcular $\mathrm{f}$ médio $=0,0087$. $\mathrm{Na}$ Tabela 1 , of foi reagrupado e correlacionado à forma clínica. $O$ coeficiente de endocruzamento foi maior entre os individuos hepa- 
Tavares-NetoJ, PrataA. Coeficiente de endocruzamento em pacientes portadores de esquistossomose mansônica. Revista da Sociedade Brasileira de Medicina Tropical 22: 45-49, jan-mar, 1989.

Tabela 1 - Coeficiente de endocruzamento correlacionado com a forma clínica da esquistossomose mansônica, em Catolândia.

\begin{tabular}{lcr}
\hline $\begin{array}{l}\text { Coeficiente de } \\
\text { Endocruzamento (f) }\end{array}$ & Forma Clínica \% (n) \\
\cline { 2 - 3 } & HI & HE \\
\hline 0 & & $73,2(41)$ \\
$1 / 4-a / 6^{a}$ & $87,5(934)$ & $14,3(8)$ \\
$1 / 32-1 / 128^{b}$ & $7,3(78)$ & $7,1(4)$ \\
Indeterminado $(\mathrm{f}>0)^{c}$ & $3,7(39)$ & $5,4(3)$
\end{tabular}

Total

$100,0(1067)$

$100,0(56)$

O. $(a+b+c): X^{2}=9,54 p<0,005$

tosplênicos $(26,8 \%)$, do que nos hepatointestinais $(12,5 \%)$. O somatório foi feito para evitar a distorção estatística dos números pequenos $\left(\mathrm{n}_{\mathrm{e}}<5,0\right)$. Assim, a diferença foi altamente significante $\left(X_{1}^{2}=9,54 \mathrm{p}\right.$ $<0,005$ ); os hepatosplènicos com coeficiente $\mathrm{f}>0$ contribuiram com $82,5 \%$ do qui-quadrado total.

$\mathrm{Na}$ Tabela 2, o coeficiente $\mathrm{f}$ foi correlacionado com os grupos raciais dos individuos. Os brancos tiveram, significatimente, mais $\mathrm{f}>0\left(\mathrm{X}_{4}^{2}=31,89 \mathrm{p}\right.$ $<0,00001)$. Aplicando o teste de bipartição do quiquadrado, os mestiços de índio e os mulatos médios não diferiram entre $\operatorname{si}\left(X_{1}^{2}=0,00 p=1\right)$, que somados não diferiram, também, dos mulatos claros $\left(X_{1}^{2}\right.$ cor $=$ $1,09 \mathrm{p}>0,20)$. Esses três grupos raciais $(\mathrm{MI}+\mathrm{MM}+\mathrm{MC})$, do mesmo modo, não diferiram dos individuos mais escuros $(\mathrm{ME}+\mathrm{N}), \mathrm{X}_{1}^{2}$ cor $=1,26 \mathrm{p}>$ 0,20 . No entanto, o conjunto dos nāo-brancos $(\mathrm{MI}+\mathrm{MC}+\mathrm{MM}+\mathrm{ME}+\mathrm{N})$ teve freqüência diferente, altamente significante, da dos brancos $\left(\mathrm{X}_{\mathrm{I}}^{2}=29,54 \mathrm{p}\right.$ $<0,00001)$. Os brancos com $\mathrm{f}>0$ contribuiram com $92,6 \%$ do qui-quadrado total $(31,89)$. Ou seja, $24,0 \%$ $(55 / 229)$ dos brancos tinham $\mathrm{f}>0$, sendo nos nãobrancos de $10,4 \%(93 / 894)$.

Tabela 2 - Coeficiente de endocruzamento, reagrupado em relação aos grupos raciais dos individuos de Catolândia-BA.

\begin{tabular}{lrrrrrr}
\hline $\begin{array}{l}\text { Coeficiente de } \\
\text { endocruzamento (f) }\end{array}$ & \multicolumn{5}{c}{ Grupo Racial $\%$ (n) } \\
\cline { 2 - 5 } & MI & B & MC & MM & ME (+N $)$ \\
\hline $\mathrm{f}=0$ & $91,5(119)$ & $76,0(174)$ & $89,0(371)$ & $91,5(195)$ & $86,6(116)$ \\
$\mathrm{f}>0$ & $8,5(11)$ & $24,0(55)$ & $11,0(46)$ & $8,5(18)$ & $13,4(18)$ \\
\hline Total & $(130)$ & $(229)$ & $(417)$ & & $(213)$ & $(134)$
\end{tabular}

a: $\mathrm{MI}=$ mestiço de índio; $\mathrm{B}=$ branco; $\mathrm{MC}=$ mulato-claro; $\mathrm{MM}=$ mulato-médio; $\mathrm{ME}=$ mulato-escuro e $\mathrm{N}=$ negro. b: 13 negros: $12(f=0)$ e 1 ( $f>0)$

$\mathrm{X}_{4}^{2}=31,89 \mathrm{p}<0,00001$ 
Tavares-Neto J, PrataA. Coeficiente de endocruzamento em pacientes portadores de esquistossomose mansônica. Revista da Sociedade Brasileira de Medicina Tropical 22: 45-49, jan-mar, 1989.

Tabela 3 - Correlação das variáveis estudadas: coeficiente de endocruzamentos ( $f$ ), raça e forma clinica da esquistossomose mansônica.

\section{Raça}

\begin{tabular}{|c|c|c|c|c|c|c|}
\hline \multirow{2}{*}{$\begin{array}{l}\text { Coeficiente de } \\
\text { Endocruzamento }\end{array}$} & \multicolumn{3}{|c|}{ Branca } & \multicolumn{3}{|c|}{ Não-Branca } \\
\hline & $\mathrm{HE}$ & $\mathrm{HI}$ & Total & $\mathrm{HE}$ & $\mathrm{HI}$ & Total \\
\hline $\begin{array}{l}f=0 \\
f>0\end{array}$ & $\begin{array}{r}5,8(10) \\
23,6(13)\end{array}$ & $\begin{array}{l}94,2(164) \\
76,4(42)\end{array}$ & $\begin{array}{r}174 \\
55\end{array}$ & $\begin{array}{l}2,9(23) \\
1,1(1)\end{array}$ & $\begin{array}{l}97,1(778) \\
98,9(92)\end{array}$ & $\begin{array}{r}801 \\
93\end{array}$ \\
\hline $\begin{array}{l}X \\
p\end{array}$ & & & $\begin{array}{c}14,82 \\
<0,0001\end{array}$ & & $\begin{array}{c}1,66^{*} \\
>0,10\end{array}$ & \\
\hline
\end{tabular}

(*) Correção de Yates

$\mathrm{Na}$ Tabela 3, a raça (branca e nâo-branca), a forma clínica (hepatosplênica e hepatointestinal) e o coeficiente de endocruzamento $(f=0$ e $f>0)$ foram correlacionados entre si. Também, somente nos indivíduos brancos, a freqüência da forma clínica, hepatosplênica, variou significantemente $(p<0,00001)$ entre os de $\mathrm{f}=0$ e $\mathrm{f}>0$; entre os não-brancos, a diferença não foi observada $(p>0,10)$. $O$ teste de Woolf 28 foi aplicado aos resultados da Tabela 3, por ser mais potente e baseado no risco relativo (RR), como se vê na Tabela 4; confirmando o comportamento diferente dos brancos, hepatosplênicos, $\operatorname{com} f>0$. Todavia, nos individuos com $\mathbf{f}=0$ a diferença não foi observada ( $>0,10)$, tanto nos brancos como nos não-brancos. Por isso, os individuos brancos e não-brancos fazem parte de amostras heterogêneas $\left(X_{1}^{2}=6,16 \mathrm{p}<0,02\right)$. Através do teste de Woolf 28 , os brancos $f>0$ tiverem risco relativo de 14,083 de apresentar a forma hepa- tosplênica. Esses resultados, também, foram analisados de outro modo, pelo teste de bipartição do quiquadrado; através dos grupos: A (branco, $f>0$ ), B (branco, $\mathrm{f}=0$ ), $\mathrm{C}$ (não-branco, $\mathrm{f}>0$ ) e $\mathrm{D}$ (não-branco $\mathrm{f}=0$ ); correlacionados com as formas clínicas, hepatosplênicas e hepatointestinal. Desse modo, a diferença foi altamente significante $\left(\mathrm{X}_{3}^{2}=45,22 \mathrm{p}<\right.$ $0,00001)$. Porém, entre os individuos dos grupos $\mathrm{C} \mathrm{e} \mathrm{D}$ não ocorreu diferença estatística ( $X_{1}^{2}$ cor $=0,47 p>$ $0,40)$, assim como os do grupo B versus o $C+D\left(X_{I}^{2}\right.$ cor $=2,31 \mathrm{p}>0,10$ ). Os indivíduos dos três grupos $(\mathrm{B}+\mathrm{C}+\mathrm{D})$ comparados aos do $\mathrm{A}$ (brancos, $\mathrm{f}>0$ ) tiveram comportamento diferente, com alta significância estatística $\left(X_{\mathrm{I}}^{2}=42,44 \mathrm{p}<0,00001\right)$. Portanto, os individuos do grupo A contribuiram com $93,8 \%$ do qui-quadrado total e tiveram risco relativo de $7,4 \mathrm{em}$ relação à forma hepatosplênica da esquistossomose mansônica.

Tabela 4 - Teste de Woolf aplicado aos resultados da Tabela 3.

\begin{tabular}{|c|c|c|c|c|c|c|c|c|c|}
\hline \multirow{3}{*}{$\begin{array}{l}\text { Coeficiente de } \\
\text { Endocruzamento (f) }\end{array}$} & \multicolumn{4}{|c|}{$\operatorname{Raça~}(\mathrm{n})$} & \multirow[b]{3}{*}{$\mathbf{R R}^{*}$} & \multirow[b]{3}{*}{$\mathrm{Y}^{*}$} & \multirow[b]{3}{*}{$\mathrm{W}^{*}$} & \multirow[b]{3}{*}{$\mathbf{X}_{1}^{2 *}$} & \multirow[b]{3}{*}{$\mathbf{P}$} \\
\hline & \multicolumn{2}{|c|}{ Branca } & \multicolumn{2}{|c|}{ Não-Branca } & & & & & \\
\hline & $\overline{\mathrm{HE}}$ & HI & $\mathrm{HE}$ & $\mathrm{HI}$ & & & & & \\
\hline$f>0$ & $13^{a}$ & $42^{b}$ & $2^{\mathrm{c}}$ & $91^{\mathrm{d}}$ & 14,083 & 2,688 & 1,635 & 11,81 & 0,001 \\
\hline$f=0$ & $11 \mathrm{e}$ & $163^{f}$ & $30 \mathrm{~g}$ & $771^{\mathrm{h}}$ & 1,734 & 0,548 & 7,594 & 2,28 & 0,10 \\
\hline
\end{tabular}

(*) $R R$ (risco relativo $=\mathrm{ad} / \mathrm{bc}$ ou eh/fg); $\mathrm{Y}=\log _{\mathrm{n}} \mathrm{RR} ; \mathrm{W}=1 / \mathrm{V} ; \mathrm{V}^{* *}=1 / \mathrm{a}+1 / \mathrm{b}+1 / \mathrm{c}+1 / \mathrm{d} ; \mathrm{X}_{1}^{2}=\mathrm{Y}^{2} \mathrm{~W}$

(**) Exemplo da primeira linha da tabela

Análise do $\mathbf{X}^{2}$

\begin{tabular}{lccl}
\hline & $\mathbf{X}^{2}$ & G.L.(a) & P \\
\hline Significância & $7,93(\mathrm{~b})$ & 1 & $<0,005$ \\
Heterogeneidade & $6,16(\mathrm{c})$ & 1 & $<0,02$ \\
\hline
\end{tabular}

a: graus de liberdade

b: $\mathbf{Y}^{\prime}=\mathbf{\Sigma} W Y / \Sigma W ; X^{2}=Y^{2} \Sigma W$

c: $X^{2}=\Sigma W Y^{2}-Y^{\prime 2} \Sigma W$ 
Tavares-NetoJ, Prata A. Coeficiente de endocruzamento em pacientes portadores de esquistossomose mansônica. Revista da Sociedade Brasileira de Medicina Tropical 22: 45-49, jan-mar, 1989.

\section{DISCUSSÃO}

Quando entre os portadores de uma doença ocorre variação racial, da recorrência familial, da resistência às formas clinicas no espectro mais grave, da concordância nos gêmeos monozigóticos, do coeficiente de consangüinidade e do suporte em resultados experimentais, existe uma sugestão da interferência do componente genético do individuo (Beiguelman ${ }^{3}$ ).

$\mathrm{Na}$ esquistossomose mansônica observa-se variação racial, porque a forma hepatosplênica é mais encontrada em brancos 25 . Nos individuos negros, aparentemente não miscigenados, essa forma clínica é rara. 21422 . Essa associação não é influenciada por fatores sócio-econômicos ${ }^{25}$; no Brasil os negróides têm pior nivel de vida. 19 .

A forma hepatosplênica concentra-se em algumas familias, ou seja, nāo tem distribuição casual, 71527 do mesmo modo na geração filial ${ }^{27}$. Isto em parte, porque a distribuição da forma hepatosplênica sofre efeito materno ${ }^{27}$, talvez por influências pré e/ou pós-natais, de origem ambiental. Quando a mãe é hepatosplênica, o risco dos filhos terem a mesma forma clinica é significantemente superior do que quando o pai é hepatosplênico. No entanto, sendo somente o pai hepatosplênico o risco dos filhos é quase três vezes superior, estatisticamente significante, do que quando ambos os genitores têm a forma hepatointestinal. 27

A resistência às formas graves, hepatosplênica, pode ser observada em estudos longitudinais, realizados em áreas hiperendêmicas, onde a freqüência raramente è superior a $10 \%, 11623$ se os critérios diagnósticos são bem definidos. Mesmo os indivíduos com carga parasitária alta ( $\geq 500$ ovos de Schistosoma mansoni/grama de fezes) e sujeitos às reinfecções podem não desenvolver a forma grave. 18

$O$ estudo em gêmeos, monozigóticos e dizigóticos, ainda não foi realizado.

Experimentalmente, Fanning e cols ${ }^{12}$, Cheever e cols 5 e Fanning \& Kazura ${ }^{11}$ relatam achados que reforçam a contribuição do componente genético na fibrose hepática, em camundongos infectados pelo $S$. mansoni.

Essas situações direcionam para a importância da constituição genética do indivíduo, no desenvolvimento da forma grave, hepatosplênica. Em alguns sistemas genéticos polimórficos, estudados por outros autores, determinados fenótipos foram mais freqüentes nos hepatosplênicos. $24 \mathrm{~A}$ região $\mathrm{D}$ do sistema de histocompatibilidade (HLA) controla a respota imune. $\mathrm{Na}$ esquistossomose mansônica, por exemplo, os portadores do haplótipo Bw44-DEN,20 têm predisposição à fibrose hepática.

A resposta imuno-inflamatória à presença do ovo do $S$. mansoni, no figado, completa com processo dinâmico de deposição do colágeno ${ }^{10}$. Os doze isóti- pos de colágeno conhecidos (Grimaud, 1987: informação pessoal) são controlados geneticamente. No entanto, falta esclarecer como a colagenogènese e a colagenólise, através de enzimas, muitas polimórficas, interagem predispondo ou não à fibrose de Symmers e posterior hipertensão portal.

Os heredogramas das familias estudadas, em Catolândia, não sugerem herança mendeliana simples, mas provavelmente multifactorial $\mathrm{e}$, possivelmente, poligênica. 27

A observação que demonstra ser o coeficiente de endocruzamento maior entre os hepatosplènicos e, notadamente, quando também da raça branca, informa que esses individuos têm redução de heterozigosidade. Ou seja, neles é mais provável o encontro de dois genes alélicos iguais. Nessa situação aumenta a probabilidade da expressão de características anômalas, de várias ordens, inclusive bioquimicas e moleculares. Assim, sendo, alteração na colagenogênese e/ou na colagenólise poderia ser observada, com repercussão clínica dependente do passo bioquimico afetado.

$O$ coeficiente $\mathrm{f}$ médio, em Catolândia, foi alto $(0,0087)$, equivalente ao coeficiente de filhos de primos em 4 ? grau $(\mathrm{f}=1 / 128)$, expressando assim a alta freqüência de casais consangüineos, principalmente no Nordeste brasileiro e na região mais distante da faixa litorânea. 13

A nossa observação, com respeito ao coeficiente de Wright ou $\mathrm{f}$, acrescenta outro dado, à hipótese do envolvimento de fatores genéticos no homem, na susceptibilidade/resistência à hepatosplenomegalia mansônica.

\section{SUMMARY}

The coefficient of inbreeding (for Wright) was studied in Catolandia, in the state of Bahia, Brazil, an area considered hyperendemic for manson schistosomiasis in a population of 1,130 inhabitants. The coefficient of inbreeding was estimated for 1,123 individuals it was classified as $f>0$ in $13.2 \%$ $(n=148)$. In the hepatosplenic group the frequency of $f>0$ was $26.8 \%$, and in the hepatointestinal group the frequency was $12.5 \%$. The frequency of the hepatosplenic diagnosis in whites who were $f=0$ did not differ from that which was observed in the negroid group. These verifications were confirmed by the Woolf's test; the relative risk of the whites, $f>0$ in acquiring hepatosplenic schistosomiasis was 14.1. These observations reinforce the influence of the genetic component in the development of the hepatosplenic form of the mansons schistosomiasis.

Key-words: Coefficient of inbreeding. Schistosoma mansoni. Hepatosplenic form. 
Tavares-Neto J, Prata A. Coeficiente de endocruzamento em pacientes portadores de esquistossomose mansônica. Revista da Sociedade Brasileira de Medicina Tropical 22: 45-49, jan-mar, 1989.

\section{REFERÊNCIAS BIBLIOGRÁFICAS}

1. Bina JC, Prata A. Evoluçāo natural da esquistossomose em uma área endêmica. In: Aspectos peculiares da infeç̧ão por Schistosoma mansoni. CEDRE/UFBa, p. 13-33, 1984.

2. Bina JC, Tavares-Neto J, Prata A, Azevedo ES. Greater resistance to development of severe Schistosomiasis in Brazilian negroes. Human Biology 50: 41-49, 1978.

3. Beiguelman B. Leprosy and genetics: a review. Revista Brasileira de Genética 6: 109-172, 1983.

4. Cardoso W. A esquistossomose mansonica no negro. Medicina Cirúrgica e Farmácia. 202/203: 89-95, 1953.

5. Cheever AW, Dunn MA, Dean DA, Duvall RH. Differences in hepatic fibrosis in ICR, C3H, and C57 BL/6 mice infected with Schistosoma mansoni. American Journal Tropical Medicine and Hygiene. 32: 13641369,1983

6. Cheever AW, Duvall RH, Hallack Jr TA. Differences in hepatic fibrosis and granuloma size in several strains of mice infected with Schistosoma japonicum. American Journal of Tropical Medicine and Hygiene 33: 602-607, 1984.

7. Conceição MJ, Coura JR. Ocorrência familiar de esplenomegalia esquistossomótica em uma área rural de Minas Gerais. Revista da Sociedade Brasileira de Medicina Tropical 13: 17-20, 1980.

8. Coura JR, Conceição MJ. Correlação entre carga parasitária de $S$. mansoni e gravidade das formas clínicas em uma comunidade rural de Minas Gerais. Revista da Sociedade Brasileira de Medicina Tropical 14: 93-97, 1981.

9. Crow JF, Kimura M. An introduction to population genetics theory. Harper \& Row ed., 1970.

10 Dunn MA. Liver collagen synthesis and degradation in Schistosomiasis. Contemporary Microbiology and Immunology 7: 198-203, 1983.

11. Fanning MM, Kazura JW. Genetic-linked variation in susceptibility of mice to schistosomiasis mansoni. Parasite Immunology 6: 95-103, 1984.

12. Fanning MM, Peters PA, Davis RS, Kazura JW, Mahmoud AA. Immunopathology of murine infection with a Schistosoma mansoni: Relationship of genetic background to hepatosplenic disease and modulation. Journal of Infectious Diseases 144: 148-153, 1981.

13. Freire-Maia N. Inbreeding in Brazil. American Journal of Human Genetics 9: 284-298, 1957.

14. Jordan P, Wehbe G. Epidemiology. In: Jordan P. Wehbe G. (ed.) Schistosomiasis. Epidemiology, Treatment and
Control. William Heinemann Med. Books, p. 227-292, 1982.

15. Kloetzel K. A sindrome hepatoesplênica na esquistossomose mansônica. (Consideraçôes sobre a incidência familiar). Revista Brasileira de Medicina 15: 263-265, 1958.

16. Kloetzel K. Splenomegaly in schistosomiasis mansoni. American Journal of Tropical Medicine and Hygiene 11: 472-476, 1962.

17. Krieger H, Morton NE, Mi MP, Azevedo E, FreireMaia A, Yasuda N. Racial admixture in north-eastern Brazil. Annals of Human Genetics 29: 113-125, 1965

18. Li CC. Populations Genetics University of Chicago Press, 1955.

19. Oliveira LEG, Porcaro RM, Araujo TCN. O lugar do negro na força de trabalho. Instituto Brasileiro de Geografia e Estatística, Rio de Janeiro, 88p., 1981.

20. Ohta N, Nishimura YK, Iuchi M, Sasazuki T. Immunogenetic analysis of patients with post-schistosomal liver cirrhosis in man. Clinical and Experimental Immunology 49: 493-499, 1982.

21. Prata A. Como caracterizar a forma hepatosplênica da esquistossomose. In: Prata A, Aboim E. (ed.). II Simpósio sobre Esquistossomose. Salvador, Bahia, p. 179184, 1970.

22. Prata A, Schroeder S. A comparison of whites and negroes infected with Schistosoma mansoni in a hyperendemic areas. Gazeta Médica da Bahia 67: 93-98, 1967.

23. Prata A, Bina JC, Barreto AC, Alecrim MG. Ensaio de controle da transmissão da esquistossomose pela oxamniquine, em uma localidade hiperendêmica. $R e-$ vista do Instituto de Medicina Tropical de São Paulo 22 (supl): 65-72, 1980.

24. Tavares-Neto J. A raça branca e a forma hepatosplênica da esquistossomose. Revista de Saúde Pública 21: 342$347,1987$.

25. Tavares-Neto J. Recorrência familial e composição racial na esquistossomose mansônica. Tese de Mestrado, Universidade de Brasilia, Brasilia, 1987.

26. Tavares-Neto J, Prata A. Regressão da forma hepatosplênica da esquistossomose após tratamento específico em relação a raça. Revista da Sociedade Brasileira de Medicina Tropical 21: 131-133, 1988.

27. Tavares-Neto J, Prata. Familial occurrence of schistosomal hepatosplenomegaly and maternal effect. Revista da Sociedade Brasileira de Medicina Tropical 22: 1318, 1989.

28. Woolf B. On estimating relation between blood group and disease. Annals of Human Genetics 19: 251-253, 1955. 